\title{
An Analysis of Fundamental ConCEPTS In THE CONCEPTUAL FRAMEWORK USING ONTOLOGY TECHNOLOGIES
}

\author{
Marthinus Cornelius Gerber \\ Department of Accounting, University of Pretoria
}

Aurona Jacoba Gerber

CAIR, CSIR Meraka and Department of Informatics, University of Pretoria

\author{
Alta van der Merwe \\ Department of Informatics, University of Pretoria
}

Accepted: March 2014

\begin{abstract}
The interpretation of financial data obtained from the accounting process for reporting purposes is regulated by financial accounting standards (FAS). The history and mechanisms used for the development of 'The Conceptual Framework for Financial Reporting' (the Conceptual Framework) as well as the financial accounting standards resulted in impressive volumes of material that guides modern financial reporting practices, but unfortunately, as is often the case with textual manuscripts, it contains descriptions that are vague, inconsistent or ambiguous. As part of the on-going initiatives to improve International Financial Reporting Standards (IFRS), the International Accounting Standards Board (IASB) promotes the development of principle-based IFRS, which aim to address the problems of vagueness, inconsistency and ambiguity.

This paper reports on the findings of a design science research (DSR) project that, as artefact, developed a first version ontology-based formal language representing the definitions of asset, liability and equity (the fundamental elements of the statement of financial position as defined in the Conceptual Framework) through the application of knowledge representation (ontology) techniques as used within computing. We suggest that this artefact may assist with addressing vagueness, inconsistencies and ambiguities within the definitions of the Conceptual Framework. Based on our findings, we include suggestions for the further development of a formal language and approach to assist the formulation of the Conceptual Framework. The project focuses on the Conceptual Framework for Financial Reporting after the incorporation of Phase $A$ in the convergence project between the Financial Accounting Standards Board (FASB) and IASB.
\end{abstract}

Key words: accounting ontology, formal ontology, financial accounting standards, conceptual framework, knowledge representation

JEL: M41

\section{1}

\section{Introduction}

A clear, consistent and unambiguous world is not the reality which accountants encounter when they compile financial statements or reports governed by financial accounting standards (Bhimani, 2008; Schipper, 2003; Tweedie, 2007; Wüstemann \& Wüstemann, 2010). The history, some of the mechanisms used to develop these standards as well as the concomitant interpretations of both US GAAP and IFRS standards, often resulted in vagueness, inconsist- encies and ambiguities in the Conceptual Framework and financial accounting standards (FASB, 2009). The Financial Accounting Standards Board (FASB) does acknowledge vagueness and inconsistencies as is evidenced in the following statement: 'The Board believes that financial reporting is both simplified and improved by removing obsolete financial accounting standards, eliminating inconsistencies, providing certain clarifications to reflect the Board's intent' (FASB, 2009).

Financial accounting standards are used to regulate the interpretation of the accounting 
data and the generation of financial statements (Camfferman \& Zeff, 2009; IFRS, 2011). Financial statements are the result of the financial reporting process, which involves gathering the financial data of a business or entity during a specific time frame, interpreting this data and then reporting the results to the various users of the financial statements (Edwards, 1989; IFRS, 2011).

Across all continents and in most countries financial accounting standards are maintained and revised by standard setting bodies. At present the two international bodies which are the most prominent drivers behind global financial accounting standards are the United States based FASB (FASB, 2014) and the London-based IASB (IASB, 2014). One of the first joint projects upon which the FASB and IASB agreed was the development of a common conceptual framework to assist the standard setters in developing, revising and interpreting financial accounting standards (FAS) (Booth, 2003; Bullen \& Crook, 2005). The stated objective of the joint conceptual framework project between the FASB and the IASB was to create a sound foundation for future FAS that are principles-based, internally consistent and internationally converged (FASAC, 2004; Bullen \& Crook, 2005). In any standardisation effort, definitions and principles of a specific semantic domain are used as foundations for the standardisation process. In the accounting domain where stakeholders should interpret financial data consistently, definitions and principles should support the process and should not be vague, inconsistent or ambiguous.

In computing there are new knowledge representation tools with the potential to address the issue of vagueness and inconsistency within semantic domain vocabularies. These tools are for instance used for the development of formal languages (aka ontologies) that are supported by technologies such as reasoners. Ontologies are formalisations based upon Description Logics (DLs), a decidable fragment of first-order logic (Baader \& Nutt, 2003; Gruninger, Bodenreider, Olken, Obrst \& Yim, 2008). DLs are a family of knowledge representation languages which are equipped with a formal semantics that provides a precise specification of the meaning represented without ambiguity. Furthermore, reasoners exist that implement logical deduction from the ontological assertions to infer additional information and consequences from the facts stated in the ontology. If asserted facts contradict each other, the inferencing of the reasoners would indicate an inconsistency (Krotzsch, Simancik \& Horrocks, 2012; Baader \& Nutt, 2003).

As stated, ontologies are often constructed in such a manner that they represent a formal language for a conceptual domain, necessarily eliminating ambiguities because the ontology engineer is forced to state assumptions explicitly. The reasoning tools facilitate the development of the language by extraction of all the logical implications, including whether all the statements in the language are inherently consistent and not contradictory. Such a formal language represented in an ontology typically describes a hierarchy of concepts within a domain and associates each concept's crucial properties with it in a precise and logical manner (Bussler, Fensel \& Maedche, 2002).

This paper reports on the first version artefact developed during a design science research project. The artefact is an ontologybased formal language for the definitions of asset, liability and equity to support the published, textual version of the Conceptual Framework for Financial Reporting.

The paper is structured as follows: section 2 provides background information on the Conceptual Framework and financial accounting standards and the position of the Conceptual Framework, and it describes related concepts. Section 3 presents some background on ontologies within computing as well as related work. In section 4 we discuss the research approach. Section 5 describes the construction of the artefact, namely an ontology-based formal language followed with the evaluation of the artefact in section 6. Our findings are discussed in section 7 and a conclusion is presented in section 8 .

\section{2}

\section{The conceptual framework and} financial accounting standards

\subsection{A brief history of the conceptual framework}

Accounting as a discipline developed centuries ago, primarily because of the need to control 
assets (Green, 1974; Edwards, 1960) and to record and report on financial transactions to investors and other users of financial statements (Edwards, 1996). Over time transactions became more sophisticated with greater demands on this recording and therefore a set of generalised rules was developed (RiahiBelkaoui, 2004). This marked the beginning of accounting practice, as these rules were developed to guide the orderly processing and more consistent reporting of financial data. As business became more sophisticated, the associated accounting practice evolved as well, but in a rather haphazard fashion. As result, the accounting rules became more voluminous and, in general, lacked consistency and coherence (Lee, Bishop \& Parker, 1996; Vorster, 2007; Edwards, 1989).

In the second half of the nineteenth century, several factors contributed towards the development of a body of accounting theory and the standardisation of accounting practices (Coffman, Tondkar \& Previts, 1993; Vorster, 2007). Several developments in this arena in the US culminated in the establishment of the FASB with the objective to formulate a conceptual framework of accounting (Storey \& Storey, 1998). Soon after its inception in 1978, the FASB published Statements of Financial Accounting Concepts No. I, entitled SFAC1Objectives of Financial Reporting by Business Enterprises. Since then, a number of SFACs have been issued by the FASB, as a whole constituting what became known as the FASB Conceptual Framework (Coffman et al., 1993; Edwards, 1989; Storey \& Storey, 1998).

Similar developments took place in Europe, and in 2001 the IASB adopted the Framework for the preparation and presentation of financial statements (Camfferman \& Zeff, 2009), which is based on the FASB's conceptual framework but is not regarded as a financial accounting standard.

In September 2002 a memorandum of understanding (The Norwalk Agreement) was signed between the FASB and the IASB (FASB \& IASB, 2002), resulting in the Joint Conceptual Framework Project of the FASB and the IASB of 2004. The purpose of the project was the revision of the respective conceptual frameworks in order to refine, update, complete and join them into a new common conceptual framework with, as purpose, the presentation of a common framework for the development of new, as well as for the revision of existing, financial accounting standards (FASAC, 2004). At a news release in September 2010 it was announced that the first stage of this joint project was complete (FASB, 2010). Although the joint conceptual framework project was suspended on 17 November 2010 (FASB \& IASB, 2010) the IASB decided on a meeting in May 2012 to continue with the conceptual framework project (IASB, 2012a; IASB, 2012b), but this time not as a joint project between the FASB and the IASB. The work in this paper is based on the Conceptual Framework published in September 2010 by the joint project. The methodology developed and the results reported in this project could assist with the remainder of the IASB conceptual framework project.

\subsection{The position of the conceptual framework in financial accounting standards}

Both the IASB and the FASB define the purpose of the financial accounting standards as a mechanism to guide accountants in detail to compile financial reports, and both view the purpose of the Conceptual Framework to be to assist standard setters in developing and revising financial accounting standards. The Conceptual Framework, therefore, should provide the foundation and context for the development of financial accounting standards (Camfferman \& Zeff, 2009; IFRS, 2011). The FASB and IASB differ in the scope of the stated purpose of the conceptual frameworks, but at present both the IASB and the FASB state that the Conceptual Framework does not override financial accounting standards. In this respect it has a lower status than specific financial accounting standards (FASAC, 2004).

The Conceptual Framework contains a section discussing its purpose and status, the objective of general purpose financial reporting, qualitative characteristics of useful financial information and, lastly, the elements of financial statements, their recognition and measurement (IFRS, 2011).

The challenge to develop a common conceptual framework that is sound, comprehensive, internally consistent, and globally 
acceptable is not trivial and it is aggravated by the fact that the domain of financial reporting is primarily a conceptual domain. However, the need for coherent financial accounting and reporting remains, thus requiring the fundamental concepts in a conceptual framework to be inherently consistent and unambiguous.

As stated, the purpose of the present project is to investigate how ontology technologies could assist with the enhancement of the Conceptual Framework. The next section provides background on ontologies within computing.

\section{3}

\section{Formal languages and ontologies}

The concept ontology was inherited from philosophy and only recently became accepted in computing (Palmer, 2001). The term ontology is currently popular and used to refer to anything from taxonomy, a domain vocabulary and a conceptual model, to a formal logicbased ontology (McGuinness, 2003). In computing an ontology is defined as a shared, formal, explicit specification of a domain, typically describing a hierarchy of concepts and associating each concept's crucial properties with it (Broekstra, Klein, Decker, Fensel, Van Harmelen \& Horrocks, 2001). In this project we use the term ontology for a formal ontology specified in a machinereadable vocabulary.

The construction and maintenance of ontologies greatly depend on the availability of logic-based languages equipped with a welldefined semantics and reasoning tools. DLs provide both the well-defined semantics and the reasoning support (Baader, Calvanese, McGuinness, Nardi, Patel-Schneider, Borgida, Lenzerini \& Rosati, 2003). Arguably the most successful application area in this regard is the biomedical field (Hahn \& Schulz, 2007; Wolstencroft, Brass, Horrocks, Lord \& Sattler, 2005), with two well-known ontologies, Snomed $\mathrm{CT}^{1}$ and the Gene Ontology $(\mathrm{GO})^{2}$. Snomed CT consists of more than 300000 concepts and a million semantic relationships where ontology technologies made it possible to perform reasoning tasks on these large-scale medical ontologies in a relatively short time (Golbreich, Horridge, Horrocks, Motik \& Shearer, 2007). As is the case in with both
SnomedCT and GO, an ontology is often used to formally specify the terminology, concepts and characteristics in a domain, thus fulfilling the role of a formal language for a specific domain (Bussler et al., 2002).

\subsection{DLs, OWL and OWL 2 semantics}

Ontologies are formalised with logic-based languages. Within computing, ontologies are defined as formalised vocabularies of terms of a domain of interest shared by a community of users (Gruber, 1995; W3C OWL Working Group, 2012). Because of the standardisation efforts of the W3C with their Web Ontology Language (OWL), most ontologies are nowadays specified using OWL.

OWL is the Web Ontology Language, which is a language that specifies structural elements that users could use to construct ontologies (Motik, Patel-Schneider \& Parsia, 2012). The language elements have formal meaning or semantics and the most recent OWL recommendation is OWL 2 (W3C OWL Working Group, 2012). OWL 2 specifies a number of profiles, which are sub-languages or syntactic subsets of OWL 2, namely OWL 2 EL, OWL 2 $\mathrm{QL}$, and OWL $2 \mathrm{RL}$. Any profile ontology is also an OWL 2 ontology and can be interpreted using the specified OWL semantics. The Direct Semantics of OWL 2 extends the semantics of the DL SROIQ, specifically with regard to data types, and the link between OWL and DLs are that any ontology specified using OWL 2 language elements could be translated into an ontology with DL axioms, and could therefore use logical inferences and reasoning to compute consequences (Motik, Patel-Schneider $\&$ Grau, 2012). The model-theoretic semantics for OWL 2 is based on sets, and for this paper it is sufficient to note that, conceptually, OWL 2 classes or concepts translate into sets. Disjoint concepts are sets that do not intersect. Sub-concepts are complete subsets of a super set. The Top- or Thing-concept is the set containing the world or all possible individuals, and the Noting-concept is the empty set, also used to indicate inconsistency if the set can never have any elements or individuals (Motik, Patel-Schneider \& Grau, 2012).

Protégé, current version 4.3 , is at present the most popular ontology engineering tool and is regarded to be the most mature. Protégé 
supports OWL 2 and the install bundle includes several reasoners such as FACT ++ that could be used to compute logical consequences of the ontology statements. The Protégé environment is open source and allows for extension by third party developers through plug-ins (Protégé Team, 2013; Stanford, 2011). For our research project we used Protégé with the bundled reasoners because of its availability, extensibility and adherence to international standards.

At this stage the decision has been made to incorporate the DOLCE foundational ontology into the refinement of the ontology artefact during later design research artefact iterations (Gangemi, Guarino, Masolo, Oltramari \& Schneider, 2002), but that discussion is beyond the scope of this paper.

The next section discusses some related work that used ontologies within the financial discipline.

\subsection{Related work}

An investigation of the literature indicated that formal ontologies with the associated technologies as focused on in this research have not readily been applied to the development of the Conceptual Framework. A similar approach was proposed in the work of Teller (Masquefa $\&$ Teller, 2010), however the present work deviates from Teller's notion of syntactic and semantic modelling. Masquefa \& Teller's (2010) approach to develop an own formalism compromises the decidability and thus reasoning support of the formalism, and we decided to adhere to the underlying DL and OWL representation language as standard in order to reap maximum benefit from the supporting ontology technologies.

Partridge (Partridge, 2002a; Partridge, 2002b) discusses some ontological choices necessary for the development of a conceptual framework from a philosophical perspective. We agree with this discussion and the necessity to argue the philosophical grounding of fundamental choices of accounting concepts as a topic of further research.

\section{Research approach}

This research project used design science research (DSR), which is research using design as a research method (Vaishnavi \& Kuechler, 2004). The goal of a DSR project is to produce a purposeful artefact that addresses a pragmatic problem, especially in cases where elements of the problem will only arise during an attempted solution, or where the problem is not completely understood (Hevner, A. R., S. T. March, J. Park \& S. Ram, 2004; Kuechler \& Vaishnavi, 2008). The driving DSR concept of 'learning by building' is especially relevant in cases where a study is testing previously untested interactions between existing artefact components, or where new, untried principles are introduced (Kuechler \& Vaishnavi, 2011). DSR is an iterative activity where the solution artefact is developed through various cycles of awareness, suggestion, development and evaluation (Vaishnavi \& Kuechler, 2004; Kuechler \& Vaishnavi, 2011). Crucial to DSR is the notion of rigour and relevance cycles, where relevance pertains to the interaction with the environment in which a real problem is identified and solved, and rigour pertains to the interaction with the scientific knowledge base where knowledge is used and contributed (Hevner \& Chatterjee, 2010).

In this research project the awareness of vagueness, inconsistencies and ambiguities within the Conceptual Framework resulted in a suggestion to use ontologies in computing to develop and ontology-based formal language to represent the concepts of the framework. For this DRS project we analysed the textual definitions of the fundamental elements of the statement of financial position as defined in the Conceptual Framework document published by the IASB, and we developed as artefact the first version artefact that is an ontology-based formal language that represents the definitions of asset, liability and equity of the Conceptual Framework. Within this development phase of the DSR project, we used an ontology engineering approach and development environment as discussed in the next section, section 4.1. The DSR evaluation phase evaluated whether these definitions could be formally represented, and whether the approach does assist with the identification of vagueness, ambiguity and inconsistency in the textual definitions. The results of the evaluation are discussed in section 6. The purpose of the DSR research project was to ascertain whether the 
use of ontologies and their associated technologies could assist with the specification of clear, consistent and unambiguous definitions of concepts in the Conceptual Framework through the development of a DSR artefact.

\subsection{Development environment}

The development of an ontology-based formal language for a domain commences with the construction of an ontology formally capturing the basic concepts and relationships of the domain. During the development cycle of the DSR project, we used as tools Protégé 4.3 with bundled reasoners (e.g. FACT++ and Pellet) to develop an OWL 2 ontology (W3C, 2009) that functions as a formal language for the selected basic definitions of the core elements necessary in the Conceptual Framework. As a development approach during the DSR development cycle, we incorporated an ontology engineering approach as described by Horridge (2009) and Noy and McGuinness (2000) that consisted broadly of the following steps:

- identification of the concepts and concept hierarchy, including disjointness;

- addition of all the relationships between concepts;

- refinement of concepts based on relationships they participate in;

- identification of definitions;

- addition of annotations, which are used for metadata or descriptions of anything that we model; and

- refinement of the ontology through various iterations of the above steps.

The next sections discuss the execution of the above steps as ontology modelling with concepts and relations necessary to represent the accounting definitions in a formal language.

\section{5}

\section{Ontology-based formal language development}

When developing an ontology for any domain, it is usually beneficial to state assumptions about the domain and approach explicitly.

\subsection{Assumptions}

For this research project we:
- adopt the view that the Conceptual Framework should encapsulate the basic definitions and principles necessary for the development of accounting standards;

- assume the position that the textual representation of the Conceptual Framework, given the role that it should play, should be sufficient without any further explanations. It should not be necessary to explain concepts or statements from third party sources;

- use only the current textual representation of the Conceptual Framework to develop the formal language and ontology;

- regard situations where the published text is unclear, ambiguous or inconsistent, as omissions and propose that this should be amended;

- accept the textual description as presented in the Conceptual Framework, but suggest that this could be augmented with an ontology-based formal language where the semantics are captured unambiguously; and

- suggest that, if inconsistencies and ambiguities exist, they do not necessarily have to be solved as the solution may be complex, but they should at least be known.

We furthermore use the terms consistency and inconsistency similarly to its use in knowledge representation with logic formalisms such as DLs, which are equipped with a formal semantics or a precise specification of the meaning intended. When facts about a domain are asserted in the language creating an ontology, these facts allow for the use of logical deduction to infer additional information from the facts stated explicitly in the ontology through reasoning (Krotzsch et al., 2012; Baader \& Nutt, 2003). If facts in the knowledge base contradict each other, the reasoning would detect an inconsistency (Antoniou \& Van Harmelen, 2009).

According to Chapter 4 of the Conceptual Framework (IASB, 2011), the elements directly related to the measurement of financial position are assets, liabilities and equity. We semantically analysed the definitions and investigated whether these definitions are precise enough to be captured in an ontology to create a formal language. We represented the concepts and relationships using ontology technologies in 
order to create a formal language for the definitions. The next sections discuss our modelling of the various concepts, and the first aspect we address is the notion of time. Concepts such as Past, Present and Future appear in the definitions in Conceptual Framework and standards, and the modelling approach adopted to represent these concepts has to be consistent throughout all the definitions.

\subsection{Modelling of time: past, present and future}

Adding temporal dimensions to OWL is not straightforward as OWL's specific logic-based formalism does not support the modelling of dynamically changing information (Krieger, 2008). OWL supports only unary and binary predicates and relations cannot directly be equipped with temporal arguments (Connor \& Das, 2011). Several solutions to the modelling of time in OWL have been proposed in the literature, either by equipping the formal semantics (Artale, Guarino \& Keet, 2008; Lutz, Wolter \& Zakharyaschev, 2008; Krieger, 2008), or through modelling constructs (Hobbs \& Pan, 2004; Ma, 2007; Connor \& Das, 2011). An ontologist would choose a solution based on the requirements that the ontology should fulfil.

In the basic definitions of the Conceptual Framework, the concepts Past, Present and
Future are pertinent. For the first version of our ontology artefact, we adopted a modelling solution, namely the basic temporal constructs of Hobs and Pan (2004) that defines (only) two classes of TemporalEntity namely Instant and Interval. The predicates begins and ends are the relations between Instants and temporal entities, which we called temporal Begins and temporalEnds in our ontology. The granularity of Instants is not specified, and can, for arguments' sake, be a date for example the date-of-reporting. The work of Hobs \& Pan (2004) allows for several formalisms regarding time, and at this stage it seems to be appropriate for the modelling we require for our ontology artefact.

Unfortunately the Conceptual Framework definitions do not clearly state what is meant with Past, Present and Future. It is straightforward to assume that Past and Future are Intervals. Present is problematic, and for the first version of our ontology, we made the choice to model Present as an Instant, with a member (individual) Dateof Reporting. Past then has a temporalEnd which is the DateofReporting, and Future temporal Begins at the DateOfReporting. This solution introduces nominals into our ontology, which could influence reasoning performance but the reasoning was still sufficient for our purposes.

Figure 1

Present as an Instant, with Past and Future as related Intervals

DateOfReporting

Present

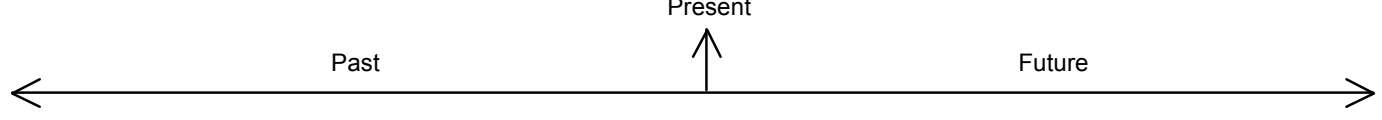

Figure 2:

The formal representation of Past, Present and Future

Internal $\subseteq$ TemporalEntity $\cap \exists$ temporalBegings.Instant $\cap \exists$ temporalEnds. Instant

TemporalEntity = Instant $\cup$ Interval

Present $\subseteq$ Instant $\quad$ Future $\subseteq$ Interval $\quad$ Past $\subseteq$ Interval

DateOfReporting : Present

Future $\subseteq \exists$ temporalBegings. \{DateOfReporting\}

Past $\subseteq \exists$ temporalEnds. \{DateOfReportin\}

\subsection{Modelling an asset}

'An asset is a resource controlled by the entity as a result of past events and from which future economic benefits are expected to flow to the entity' (IASB, 2011).

When we analysed and decomposed this 
definition, we identified Resource, Entity, Event and Benefit as disjoint concepts to be used for representing Asset. The refine- ments on the concepts are formally represented in Figure 3.

Figure 3

Formal representation of Asset

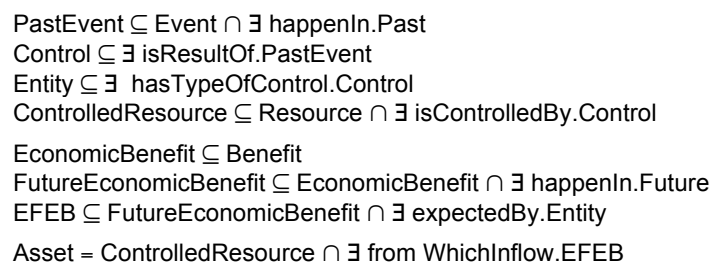

In the modelling of Asset, we found the following:

- Benefit has sub-concepts EconomicBenefit and FutureEconomicBenefit.

- The concept of Control is implied because Control is the result of past events. The concept of Control needs further refinement in later versions. There are, for instance, different types of control. Modelling Control as a concept implies the introduction of object properties that relates Entity to Control via hasTypeofControl and Resource to Control via iscontrolled By. A controlledResource is a Resource that is controlled by a control.

- The use of the term 'expected' is not clear. It could refine FutureEconomicBenefit or flow (which is a relation). In other words, does the definition expect flow of benefit, or does it expect future economic benefit? We made the modelling decision to associate it with economic benefit and thus we created an ExpectedFuture EconomicBenefit or the EFEB concept as a sub-concept of FutureEconomic Benefit that is also expected by an entity.

- Finally, the representation definition of an Asset is a ControlledResource and fromWhichInflow. EFEB as depicted in Figure 3.

\subsection{Modelling a liability}

'A liability is a present obligation of the entity arising from past events, the settlement of which is expected to result in an outflow from the entity of resources embodying economic benefits' (IASB, 2011).

We identified obligation and settlement as additional disjoint concepts necessary for modelling a liability. The refinements on the concepts are depicted in Figure 4.

Figure 4

Liability

Obligation $\subseteq \exists$ hasSettlement.Settlement $\cap \exists$ isResultOf.PastEvent

PresentObligation $\subseteq$ Obligation $\cap \exists$ happenIn.Present

Entity $\subseteq \exists$ hasObligation.Obligation

ResourceEmbodyingEconomicBenefit $\subseteq$ Resource $\cap \exists$ embodies. EconomicBenefit

Settlement $\subseteq \exists$ fromWhichOutflow.ResourceEmbodyingEconomicBenefit

ExpectedSettlement $\subseteq$ Settlement $\cap \exists$ expectedBy.Entity

Liability $=$ PresentObligation $\cap \exists$ hasSettlement.ExpectedSettlement

When modelling liability, we found the following:

The outflow of resources embodying economic benefits refines settlement. However, this implies the addition of a concept Resource
EmbodyingEconomicBenefit that is a Resource that embodies some EconomicBenefit. However, the concept and meaning of a resource embodying economic benefit needs clarification. According to the Conceptual 
Framework only those resources that comply with the definition of an asset belong to the entity and can be recognised as assets of the specific entity. Only those resources that can be defined as assets of a specific entity can embody an outflow of economic benefit. A specific entity cannot embody the outflow of any resource, but only resources that belong to that specific entity. This definition should be integrated with the definition of an asset.

- The use and meaning of expected is problematic as it is again not clear whether it refines Settlement or flow (which is a relation). Does the definition expect the flow or expect the resulted settlement? We made a modelling decision to create an ExpectedSettlement concept as a Settlement that isExpectedBy some Entity.

- Finally, the formal definition of a Liability is a Presentobligation and it has Settlement.ExpectedSettlement.

\subsection{Modelling equity}

'Equity is the residual interest in the assets of the entity after deducting all its liabilities' (IASB, 2011).

Analysing this definition, we identified Interest as an additional and disjoint concept to be used for equity. Residual Interest is a type of Interest that has to be refined further as it is interest in assets after deducting liabilities. One way to formalise the notion of deduction in a DL ontology is through set difference or formally: $B \backslash A=\{x \in B \mid x \notin A\}^{3}$. For our definition it is viable to use set difference and therefore Equity was initially modelled as Asset and not Liability.

However, this definition of Equity resulted in an inconsistency in Protégé. The reasoner inferred that the Equity and therefore Asset concepts are inconsistent (or sub-concepts of Nothing) as indicated in Figure 5.

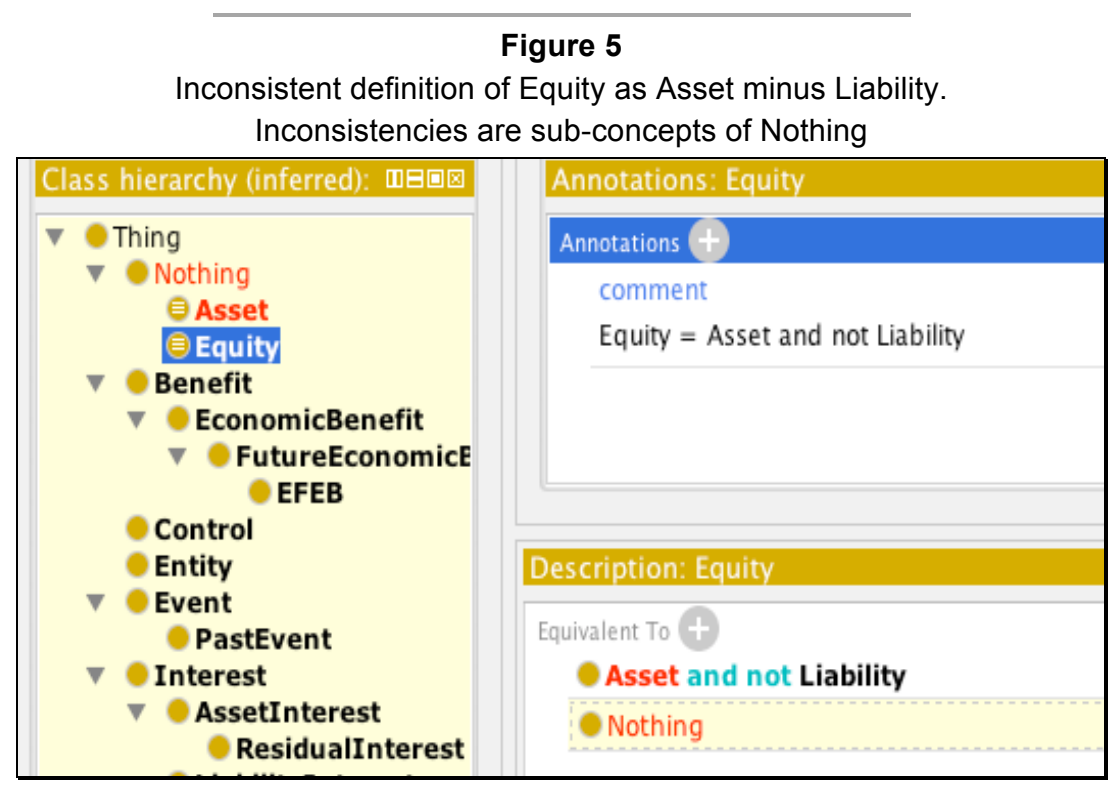

The definition is inconsistent because, from the previous definitions, an Asset is a refined Resource and a Liability is a refined obligation. An Asset and an Obligation are derived from different and disjoint concepts and therefore no concept can be created that is a combination of them, in this case deducting Liability from Asset.

\subsection{Further modelling of equity}

To remove the detected inconsistency, we did further semantic analysis of the definition of equity. The definition implies a value, or in the terminology of the definition, an interest to be associated with both assets and liabilities because residual interest is the result. 
The inconsistency in the text is caused by the implicit assumption that asset and liability have associated values, which also implies that equity must have a value, even though this implied value is never stated in the text. How this implied that values should be determined is also absent from the definitions.

We therefore made a modelling decision to add AssetInterest and LiabilityInterest as types of Interest specifically to be able to indicate that Asset and LiabilityhasInterest some Asset Interest and LiabilityInterest respectively as indicated in Figure 6.

Furthermore, using set difference for deduction in this ontology:

- Residualinterest is the set difference between Interest and LiabilityInterest.

- Another decision necessary here in order to model the set difference properly is that all Interest is either AssetInterest or LiabilityInterest.

- Finally, the formal definition of Equity is Interest and not LiabilityInterest.

Figure 6

Equity defined through interest values

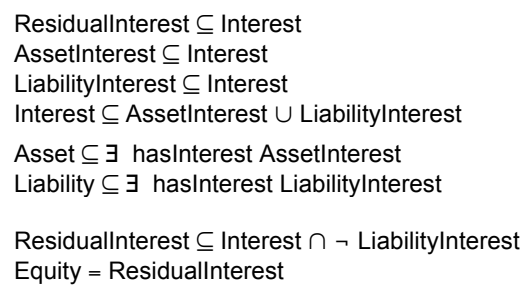

\subsection{Logical inferences of equity modelling}

In the Protégé 4 ontology editor the inferred concept hierarchy depicts all the consequences of our asserted statements after the execution of reasoning. Figure 7 presents the Residual Interest concept, which is defined as Interest and not LiabilityInterest in the right-hand window. The derived logical inferences indicate that Equity = Residual Interest as well as that both Equity and Residual Interest are sub-concepts of AssetInterest. This derived information provides compelling evidence for the benefit of these technologies for tasks such as the creation of unambiguous definitions in the conceptual framework, especially when the domain is large and complex.

\section{6}

\section{Evaluation}

The purpose of the research project was to ascertain whether the use of ontologies and their associated technologies could assist with the specification of clear, consistent and unambiguous definitions of concepts in the Conceptual Framework through the development of a DSR artefact. Our results indicate evidence that this is the case, as indicated below:

- Several unclarities exist with regard to concepts such as present, economic benefit, control, and expected. We made certain modelling choices with regard to the representation of these concepts resulting in definitions that are clearer, but these choices need to be verified by domain experts. However, for the purpose of our evaluation, ontologies assisted with the specification of the clear definitions of concepts.

- During the representation of liability, we encountered the concept of a resource embodying economic benefit, which is potentially contradictory and needs clarifycation. The Conceptual Framework asserts that only those resources that comply with the definition of an asset belong to the entity and are recognised as assets of the specific entity. Only those resources that can be defined as assets of a specific entity (not any resource as stated) can embody an outflow of economic benefit, as depicted in Figure 8 . With regard to our evaluation, this result provides evidence that ontologies could assist with 'tightening up' of definitions that are too vague. 
Figure 7

The inferred concept hierarchy with the inferred fact that Residuallnterest is AssetInterest given the current asserted facts

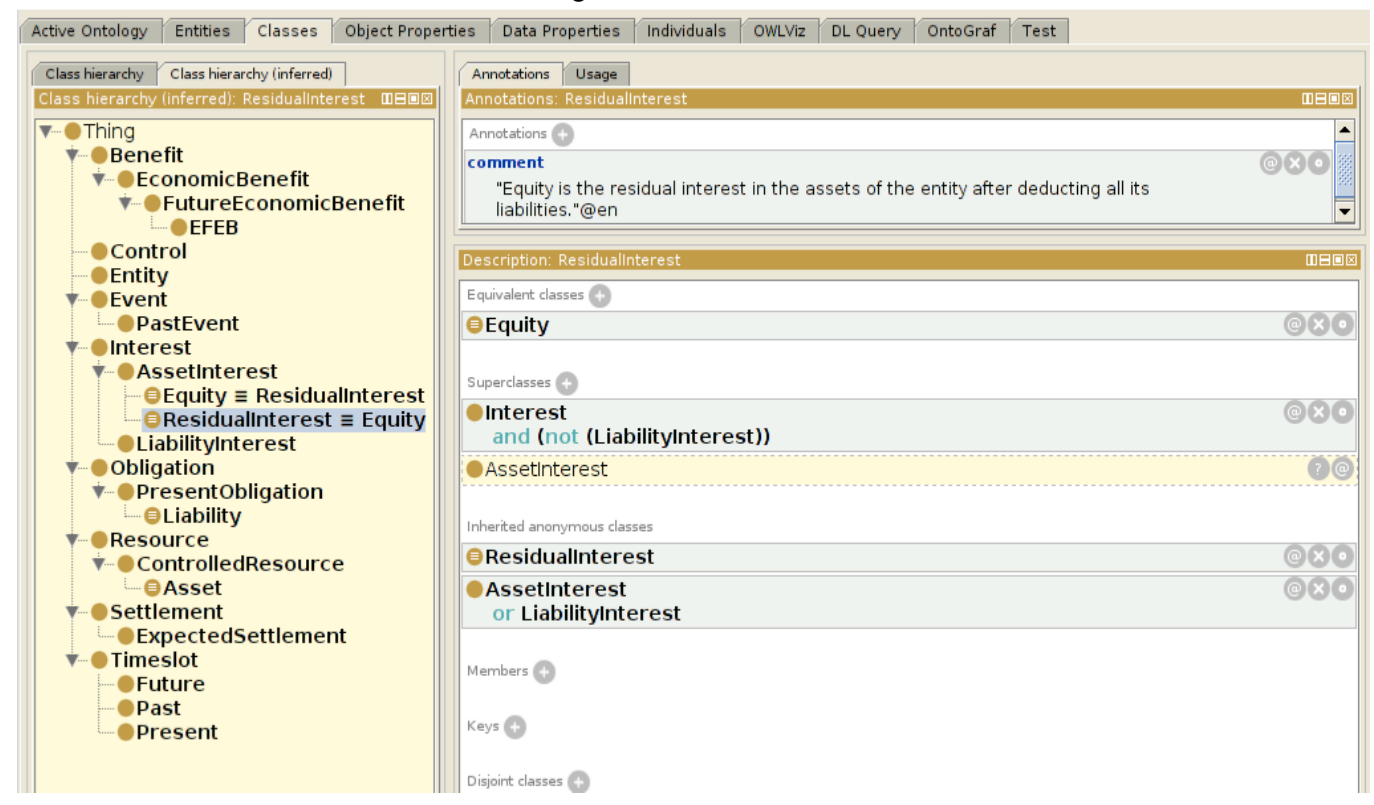

\section{Figure 8}

Only resources under control of an entity (i.e. assets) can embody an outflow of economic benefit from the entity, not any resource

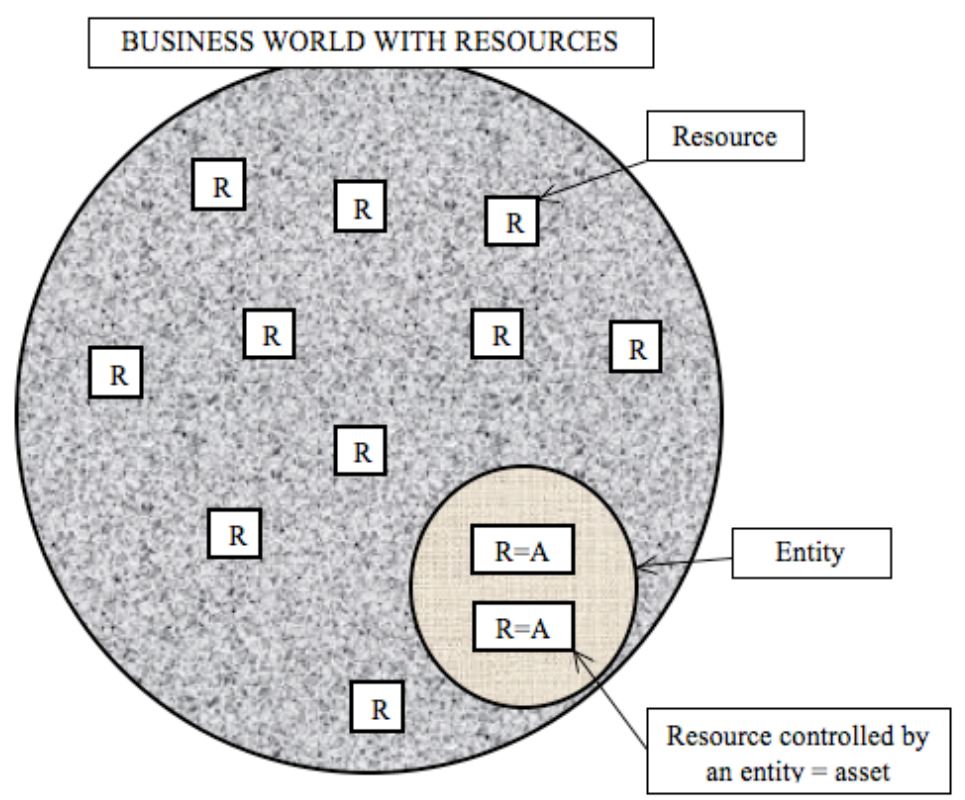


- Inconsistencies: during the representation of equity, we modelled assertions exactly as stated in the text. This resulted in an inconsistency as an Asset was defined as a refined Resource and a Liability is a refined obligation. Assets and obligations are derived from different and disjoint concepts and therefore no concept can be created that is a combination of both. This result indicated that certain information, namely the value of an Asset and Liability, were implied and not stated explicitly. The approach therefore allowed us to detect inconsistencies in the stated text, as well as implied assumptions.

- Using the reasoners that computed the logical consequences of our asserted statements, it was possible to derive additional information, namely that Equity = Residualinterest as well as that both Equity and Residualinterest are subconcepts of AssetInterest. These consequences need to be verified by domain experts, but the value of the unexpected results that could be derived from asserted facts is evident. Such facts could be used to refine a model, and if consequences are not correct, it is necessary to revisit the assertions that, by logical implication, gave the inferred result. We argue that this is a powerful tool when standard setters refine the definitions in the Conceptual Framework.

\section{7}

\section{Findings}

We constructed a first version ontology-based formal language representing the definitions of asset, liability and equity. The results and experience indicate that it is plausible to argue that an ontology-based formal language could be constructed to support the Conceptual Framework. The most significant findings are that, even with basic assertions, it was possible to identify unclear and vague concepts, as well as contradictions, inconsistencies and the unexpected consequences of assertions that are not evident at first glance of the published text. Furthermore, it was possible to create an ontology-based formal language for the definitions where the meaning is much less vague, even though there is not necessarily consensus about current language.

Vagueness, inconsistencies and ambiguities lead to an inconsistency in the model if they are not clarified and it could have several consequences for stakeholders using the basic definitions. During financial reporting important decisions are made based on these models and different decisions could lead to contradictory financial interpretations and reports.

The refinement and usefulness of the artefact ontology-based formal language is a topic for further research, as well as the construction of an approach and environment for users to apply the formal language. In addition, ontology engineering is essentially a collaborative exercise and a formal language should reflect consensus about a domain. From the results we found in this first version of an ontology for the Conceptual Framework reported on in this paper, it is necessary to establish an initiative including all stakeholders for the further development of a formal language representing the Conceptual Framework.

We summarise the additional findings as indicated below:

- A formal ontology of the element definitions could only be constructed after making several modelling decisions about aspects that were unclear from the printed text. These decisions and interpretations are based on assumptions that may not be correct. However, any stakeholder intending to use the definitions will be confronted with the same ambiguities and lack of information and clarity. It is therefore useful to construct a formal model with explicit meaning that could be refined later rather than using an unclear definition.

- Familiarity with the logic of the DL languages remains a prerequisite for formal DL-based ontology construction, irrespective of the tools used.

- The current tools (notably Protégé 4.3 with its bundled reasoners such as FACT++) are open source, but still provided us with sufficient support to construct our ontology. The availability of mature and standardised tools is an incentive to embrace a project such as described in this paper. However, it is important to note that available ontology tools still have limited functionality for example graphical interfaces as well as 
complex explanations of derived consequences. The lack of tools that assist with ontology debugging, such as explaining an inference result, remains a significant drawback, especially when models are complex.

\subsection{Possible benefits for standard setters}

Since ontology-based formal languages are based on concepts and the relations between the concepts, the concepts used must be clear and unambiguously defined. Defining concepts unambiguously strips the concepts of assumptions that form part of the historical use of a concept, which, without precise clarification of the meaning of the concept, has the effect that different readers may attach different meanings to the same concept.

The re-usability of unambiguous concepts is of value in the application of the concepts within the wider accounting domain such, as derived financial accounting standards with the associated interpretations. Re-usability of concepts has the following benefits:

i. The setting of well-crafted principle-based standards.

ii. Should assist standard setters to indicate how the principles in the standards compare with the Conceptual Framework. Any departure from the principles could be explained in an annotation.

A formal representation language empowers a standard setter to formulate a clear motivation on whether to accept or reject specific inconsistencies and ambiguities. As the meaning of a definition in a text is unambiguously clear, discussion between accountants could concentrate on the merits of a principle or concept (which may be inconsistent) from a theoretical perspective without getting trapped between the possible meanings of the different principles or concepts. Furthermore, it is possible to compare and test consistencies between different definitions and concepts.

\section{8}

\section{Conclusion}

From the first version of the artefact construction of an ontology-based formal language for the Conceptual Framework, there is evidence that the construction of a formal language using ontology technologies could play a substantial role to enhance the quality, clarity and re-usability of the Conceptual Framework definitions. Ontology statements are explicit and precise, and consequences of assertions can be exposed using reasoning technologies. Such a formal language represents the required definitions of elements in a much more precise and unambiguous manner than the text format used at present and, when used in conjunction with the text, it should promote unambiguously, clarity and consistent financial accounting standards and interpretations globally.

Based on the results of our project, the following suggestions are proposed for inclusion into an approach that could address the enhancement of the Conceptual Framework:

- The role and status of the Conceptual Framework within the financial accounting standards should be clarified.

- For unambiguous financial accounting standards, the Conceptual Framework should possibly prescribe all definitions and principles that guide financial accounting standards and interpretations. The Conceptual Framework as semantic domain model should provide a complete representation of all the principles that would regulate the specific domain it represents.

- If the Conceptual Framework provides the context and principles for financial accounting standards development, the content of the Conceptual Framework should be clearly specified. This content should include clear definitions of elements. All financial accounting standards and interpretations should preferably adhere to the Conceptual Framework definitions. Any deviations from the set principles and definitions should be noted and explained.

- From the work described in this paper there is evidence that tools such as ontology technologies could assist with the creation of clear and unambiguous definitions for inclusion in the Conceptual Framework. Such tools should be identified and included in financial accounting standards development processes.

- A rigorous ontology engineering approach should be adopted. This approach should include the participation of stakeholders in 
order to establish consensus about the core definitions, concepts and relations in the domain.

- Given the results of our investigation into the use of formal ontologies for the development of consistent and unambiguous definitions for the elements of the statement of financial position, we conclude that in the accounting world we can still live with inconsistencies if they are known, because we can manage them (e.g. the equity definition), but we cannot live with ambiguities even though they are known, because they can result in diverse interpretations with different results based on the same definitions and principles.

Endnotes

$1 \mathrm{http}: / / \mathrm{www}$.intsdo.org/snomed-ct/

2 http://www.geneontology.org/

3 DL is formally based on set theory and conceptually; mathematical deduction is modelled with set difference.

\section{References}

ANTONIOU, G. \& VAN HARMELEN, F. 2009. Web ontology language: OWL. In, Handbook on ontologies, S. Staab \& D. Rudi Studer. (eds.) Springer: Berlin Heidelberg:91-110.

ARTALE, A., GUARINO, N. \& KEET, C.M. 2008. Formalising temporal constraints on part-whole relations. Journal of Web Semantics, 5:46.

BAADER, F., CALVANESE, D., MCGUINNESS, D., NARDI, D., PATEL-SCHNEIDER, P., BORGIDA, A., LENZERINI, M. \& ROSATI. R., 2003. The description logic handbook: Theory, implementation, and applications. Accountancy. vol. 44. Cambridge: Cambridge University Press.

BAADER, F. \& NUTT, W. 2003. Basic description logics. In The description logics handbook: Theory, implementation and applications, Baader, F., Calvanese, D. McGuinness, D. Nardi, D. \& Patel-Schneider, P. (eds.) Cambridge: Cambridge University Press:47-100.

BHIMANI, A. 2008. The role of a crisis in reshaping the role of accounting. Journal of Accounting and Public Policy, 27(6):444-454.

BOOTH, B. 2003. The conceptual framework as a coherent system for the development of accounting standards. Abacus, 39(3):310-324.

BROEKSTRA, J., KLEIN, M., DECKER, S., FENSEL, D., VAN HARMELEN, F. \& HORROCKS, I. 2001. Enabling knowledge representation on the web by extending RDF schema. Accounting, Organizations and Society, ACM 1-5811:467. Addison Wesley Professional.

BULLEN, H.G. \& CROOK, K. 2005. Revisiting the concepts: A new conceptual framework project. FASB and IASB. Available at: http://www.fep.up.pt/disciplinas/mbf904/conceptual frameworks_paper.pdf. [accessed 2014-08-03].

BUSSLER, C., FENSEL, D. \& MAEDCHE, A. 2002. A conceptual architecture for semantic web enabled web services. ACM SIGMOD Record, 31(4):24.

CAMFFERMAN, K. \& ZEFF, S.A. 2009. Financial reporting and global capital markets: A History of the inernational accounting standards committee 1973-2000. Upper Saddle River, N.J: Oxford University Press. COFFMAN, E.N., TONDKAR, R.H. \& PREVITS, G.J. 1993. Historical perspectives of selected financial accounting topics. MIS Quarterly, 13. Irwin, Boston MA.

CONNOR, M.J.O. \& DAS, A.K. 2011. A method for representing and querying temporal information in OWL:97-110,

EDWARDS, J.D. 1960. Early bookkeeping and its development into accounting. Business History Review, 34(04):446-458.

EDWARDS, J.R. 1989. A history of financial accounting. New York: Routledge.

EDWARDS, J.R. 1996. Financial accounting practice 1600-1970: Continuity and change. in accounting history from the Renaissance to the present: A remembrance of Luca Pacioli, Lee, T.A., Bishop, A. \& Parker, R.H. (eds.) New York: Garland Publishing, Inc.:31-70.

FASAC. 2004. Revisiting the FASB's conceptual framework. Norwalk: Connecticut. Available at: http://www.fasb.org/jsp/FASB/Document_C/DocumentPage\&cid=1218220253854 [accessed 2014-08-03]. 
FASB. 2009. Financial accounting series: Exposure draft: Proposed statement of financial accounting standards. File Reference No: 1670-100.

FASB. 2010. News release 09/28/10: IASB and US FASB complete first stage of conceptual framework. New York, NY, USA: ACM Press. Available at: http://www.fasb.org/cs/ContentServer?c=FASBContent C\&pagename=FASB/FASBContent_C/NewsPage\&cid=1176157497474 [accessed 2014-08-03].

FASB. 2014. Financial accounting standards board: Web page. Available at: http://www.fasb.org/jsp/ FASB/Page/LandingPage\&cid=1175805317407 [accessed 2014-08-03].

FASB and IASB. 2002. The Norwalk agreement. Available at: http://www.fasb.org/news/memorandum.pdf [accessed 2014-08-03].

FASB and IASB. 2010. Minutes of November 17, 2010, Joint board meeting; conceptual framework. Available at: http://www.fasb.org/cs/ContentServer?site=FASB\&c=Document_C\&pagename=FASB/ Document_C/DocumentPage\&cid=1176157943897 [accessed 2014-08-03].

GANGEMI, A., GUARINO, N., MASOLO, C., OLTRAMARI, A. \& SCHNEIDER, L. 2002. Sweetening ontologies with DOLCE. Knowledge engineering and knowledge management: Ontologies and the semantic Web:166-181. Springer Berlin Heidelberg.

GOLBREICH, C., HORRIDGE, M., HORROCKS, I., MOTIK, B. \& SHEARER, R. 2007. OBO and OWL: Leveraging semantic web technologies for the life sciences. The Semantic Web, 22:169-182. Springer Berlin Heidelberg.

GREEN, W.L. 1974. History and survey of accountancy. Osaka: Nihon Shoseki, LTD.

GRUBER, T.R. 1995. Toward principles for the design of ontologies used for knowledge sharing? International Journal of Human-Computer Studies, 43(5-6):907-928.

GRUNINGER, M., BODENREIDER, O., OLKEN, F., OBRST, L. \& YIM, P. 2008. Ontology summit 2007 - Ontology, taxonomy, folksonomy: Understanding the distinctions. Applied Ontology, 3:191-200.

HAHN, U. \& SCHULZ, S. 2007. Ontological foundations for biomedical sciences. Artificial Intelligence in Medicine, 39(3):179-182.

HEVNER, A. \& CHATTERJEE, S. 2010. Design research in information systems. Information Systems, 22:179-194.

HEVNER, A.R., MARCH, S.T., PARK, J. \& RAM, S. 2004. Design science in information systems research. MIS Quarterly, 28(1):75-105.

HOBBS, J. R. \& PAN, F. 2004. An ontology of time for the semantic web. ACM Transactions on Asian Language Processing (TALIP): Special issue on Temporal Information Processing, 3(1):66-85.

HORRIDGE, M. 2009. Protege OWL tutorial. Avialable at: http://130.88.198.11/tutorials/protegeowltutorial/ [accessed 2014-08-03].

IASB. 2011. The conceptual framework. London, United Kingdom: IASB. Available at: http://eifrs.iasb.org/ eifrs/bnstandards/en/framework.pdf [accessed 2014-08-03].

IASB. 2012a. IASB Update May 2012. IASB Update. Available at: http://media.ifrs.org/IASBupdateMay 2012.html\#7 [accessed 2014-08-03].

IASB. 2012b. Feedback statement: Agenda consultation 2011. London, United Kingdom: IASB. Available at: http://www.ifrs.org/Current-Projects/IASB-Projects/IASB-agenda-consultation/Documents/FeedbackStatement-Agenda-Consultation-Dec-2012.pdf [accessed 2014-08-03].

IASB. 2014. International accounting standards board: Web Page. Available at: http://www.ifrs.org/Pages/ default.aspx [accessed 2014-08-03].

IFRS. 2011. IFRS standards. London, United Kingdom: IFRS Foundation.

KRIEGER, H. 2008. Where temporal description logics fail : Representing temporally-changing. KI2008: Advances in Artificial Intelligence. Lecture Notes in Computer Science, 5243:249-257.

KROTZSCH, M., SIMANCIK, F. \& HORROCKS, I. 2012. A description logic primer. CoRR abs/1201.4.

KUECHLER, B. \& VAISHNAVI, V. 2008. On theory development in design science research: Anatomy of a research project. European Journal of Information Systems, 17:489-504.

KUECHLER, B. \& VAISHNAVI, V. 2011. Extending prior research with design science research : Two patterns for DSRIS project generation. Desrist 2011:166-175. Springer Berlin Heidelberg.

LEE, T.A., BISHOP, A. \& PARKER, R.H. (eds.) 1996. Accounting history from the Renaissance to the present: A remembrance of Luca Pacioli. New York and London: Garland Publishing, Inc. 
LUTZ, C., WOLTER, F. \& ZAKHARYASCHEV, M. 2008. Temporal description logics: A survey. 2008 15th International Symposium on Temporal Representation and Reasoning:3-14.

MA, J. 2007. Ontological considerations of time, meta-predicates and temporal propositions. Applied Ontology, 2:37-66.

MASQUEFA, B., \& TELLER, P. 2010. Towards a theoretical framework for the diffusion of accounting and control system. 2010 Fourth International Conference on Research Challenges in Information Science (RCIS):599-606. IEEE.

MCGUINNESS, D.L. 2003. Ontologies come of age. In Spinning the semantic web: bringing the World Wide Web to its full potential, Fensel, D., Hendler, J., Lieberman, H. \& Wahlster, W. (eds.) 1-14. (1 $1^{\text {st }}$ ed.) MIT Press.

MOTIK, B., PATEL-SCHNEIDER, P.F. \& GRAU, B.C. 2012. W3C recommendation: OWL 2 web ontology language direct semantics ( $2^{\text {nd }} \mathrm{ed}$.).

MOTIK, B., PATEL-SCHNEIDER, P.F. \& PARSIA, B. 2012. W3C recommendation: OWL 2 web ontology language structural specification and functional-style syntax $\left(2^{\text {nd }} \mathrm{ed}.\right)$.

NOY, N.F. \& MCGUINNESS, D.L. 2000. Ontology development 101: A guide to creating your first ontology. Stanford, CA, 94305.

PALMER, S.B. 2001. The semantic web: An introduction. The CPA Journal, 139.

PARTRIDGE, C. 2002a. A new foundation for accounting: Steps towards the development of a reference ontology for accounting. Technical Report 23/02, LADSEB-CNR, Padova, Italy.

PARTRIDGE, C. 2002b. Shifting the ontological foundation of accounting's conceptual scheme. England: BORO program.

PROTÉGÉ TEAM. 2013. The protégé ontology editor. Available at: http://protege.stanford.edu/ [accessed 2014-08-03].

RIAHI-BELKAOUI, A. 2004. Accounting theory. London: International Thomson Business.

SCHIPPER, K. 2003. Principles-based accounting standards. Accounting Horizons, 17(1):61.

STANFORD. 2011. Protege programming development kit (PDK).

STOREY, R.K. \& STOREY, S. 1998. The framework of financial accounting concepts and standards. Norwalk, Connecticut: Financial Accounting Standards Board.

TWEEDIE, D. 2007. Can global standards be principle based? Journal of Applied Research in Accounting and Finance, 2(1):3-8.

VAISHNAVI, V. \& KUECHLER, W. 2004. Design research in information systems. $B R W$. Available at: http://www.citeulike.org/group/4795/article/6505471 [accessed 2014-08-03].

VORSTER, Q. 2007. The conceptual framework, accounting principles and what we believe is true. Accountancy SA; Accounting \& Tax Periodicals: 30.

W3C. 2009. OWL 2 Web ontology language: Document overview. Available at: http://www.w3.org/ [accessed 2014-08-04]

W3C OWL Working Group. 2012. W3C recommendation: OWL 2 web ontology language document overview ( $2^{\text {nd }}$ ed.) Available at: http://www.w3.org/TR/owl2-overview/ [accessed 2014-08-04].

WOLSTENCROFT, K., BRASS, A., HORROCKS, I., LORD, P. \& SATTLER, U. 2005. A little semantic web goes a long way in biology. Lecture Notes in Computer Science: The Semantic Web - ISWC 2005 3729(2):786-800.

WÜSTEMANN, J. \& WÜSTEMANN, S. 2010. Why consistency of accounting standards matters: a contribution to the rules-versus-principles debate in financial reporting. Abacus, 46(1):1-27. 